\title{
A Comparative Study on the Effect of Temperature and Concentration on Density, Sound Velocity and their Derived Properties for Diclofenac Potassium in Aqueous Urea Media
}

\author{
Sulochana Singh ${ }^{1(\mathbb{D})}$, Kshirabdhitanaya Dhal ${ }^{1}{ }^{(\mathbb{D}}$, Malabika Talukdar ${ }^{1, *}$ (D) \\ 1 Department of Chemistry, ITER, SOA Deemed to be University, Bhubaneswar, Odisha, India \\ * Correspondence: malabikatalukdar@soa.ac.in;
}

Scopus Author ID 36603451700

Received: 18.04.2020; Revised: 7.05.2020; Accepted: 7.05.2020; Published: 13.05.2020

\begin{abstract}
The present study has undertaken experimental measurements of ultrasonic velocity (U) and density (d) of solutions of Diclofenac potassium in water and in aqueous urea media of different molar concentrations. Computation of physico-chemical parameters like apparent molar volume $\left(\mathrm{V}_{\Phi}\right)$, limiting apparent molar volume $\left(\mathrm{V}_{\Phi}^{0}\right)$, apparent molar expansibility $\left(\mathrm{E}_{\Phi}\right)$, limiting apparent molar expansibility $\left(\mathrm{E}_{\Phi}^{0}\right)$, molar isentropic compressibility $\left(\mathrm{K}_{\mathrm{S}}\right)$, apparent molar isentropic compressibility $\left(\mathrm{K}_{\mathrm{s}, \phi}\right)$, molar adiabatic compressibility $(\mathrm{W})$, molar isothermal compressibility $\left(\mathrm{K}_{\mathrm{T}}\right)$, acoustic impedance $(\mathrm{Z})$, free volume $\left(V_{f}\right)$, internal pressure $\left(\pi_{i}\right)$, relative association $\left(R_{A}\right)$, coefficient of thermal expansion $(\alpha)$ and van der Waals constant (b) was done by using the experimentally obtained values. The influence of varying concentrations of Diclofenac potassium as well as of urea in solutions and the variation of the investigating temperatures on the above mentioned parameters are expected to reveal the nature of different molecular interactions existing in the drug solutions.
\end{abstract}

Keywords: Pharmaceutical waste; physico-chemical properties; molecular interaction; structural effect.

(C) 2020 by the authors. This article is an open access article distributed under the terms and conditions of the Creative Commons Attribution (CC BY) license (https://creativecommons.org/licenses/by/4.0/).

\section{Introduction}

Pharmaceutical wastes are frequently found in aquatic medium, be it wastewater effluents, surface waters, ground waters or drinking water [1]. An extensive literature survey has been done in relation to the environmental occurrence of pharmaceutical wastes. It has become a matter of concern with respect to human and animal health and environment. A nonsteroidal drug Diclofenac (potassium or sodium salt of diclofenac is commonly referred to as diclofenac) is prescribed to treat pain, fever, swelling etc. Diclofenac is one of the top 10 most frequently detected compounds in pharmaceutical wastes [2]. As it does not fully degrade in waste water treatment plants a continuous release of this drug in waste water results in increasing concentration in receiving water bodies. A recurring exposure to this drug may affect the metabolism of aquatic species and microbes [3]. A clear understanding of molecular interactions of diclofenac potassium in water in the presence of impurities like urea (an agricultural waste found in wastewater) demands an extensive study on physico-chemical properties of the drug solution. Urea acts as a hydrotropic agent and enhances the aqueous solubility of diclofenac potassium. 
In the present study, physico-chemical properties of solutions of diclofenac potassium in 2, 3 and $4 \mathrm{M}$ urea have been determined experimentally in laboratory conditions. Aqueous solutions with different concentrations of diclofenac potassium and of urea were prepared. Experiments were carried out on measurement of sound velocity (U) in drug solutions in aqueous urea at $298.15 \mathrm{~K}$. Density (d) values were also measured for these solutions at four different temperatures in the range of 298.15-313.15K. Several other parameters were calculated from the above mentioned experimental data. Apparent molar volume $\left(\mathrm{V}_{\Phi}\right)$, limiting apparent molar volume $\left(\mathrm{V}_{\Phi}^{0}\right)$, apparent molar expansibility $\left(\mathrm{E}_{\Phi}\right)$ and limiting apparent molar expansibility $\left(\mathrm{E}_{\Phi}^{0}\right)$ were derived from the density values of the drug solutions with different concentrations at different temperatures. Ultrasonic velocity data were used to evaluate molar isentropic compressibility $\left(\mathrm{K}_{\mathrm{S}}\right)$, apparent molar isentropic compressibility $\left(\mathrm{K}_{\mathrm{s}, \Phi}\right)$, molar isothermal compressibility $\left(\mathrm{K}_{\mathrm{T}}\right)$, molar adiabatic compressibility $(\mathrm{W})$, acoustic impedance $(\mathrm{Z})$, free volume $\left(V_{f}\right)$, internal pressure $\left(\pi_{i}\right)$, relative association $\left(R_{A}\right)$, van der Waals constant $(b)$ and coefficient of thermal expansion $(\alpha)$ at $298.15 \mathrm{~K}$. All these experimental and derived parameters were analysed to focus light on various molecular interactions and structural effects of the drug under investigation in solutions [4-10].

\section{Materials and Methods}

\subsection{Chemicals.}

Diclofenac potassium and urea of $>99 \%$ purity were supplied by Orissa Drugs \& Chemicals Ltd Bhubaneswar, Odisha and Laboratory Chemicals Bhubaneswar, Odisha respectively. Conductivity water of specific conductance of $10^{-6} \mathrm{Scm}^{-1}$ was used for making all the solutions.

\subsection{Preparation of solutions.}

The stock solution was prepared on a molar basis $(\mathrm{mol} / \mathrm{v})$ by dissolving calculated mass of diclofenac potassium in required volumes of water and of 2, 3 and $4 \mathrm{M}$ of aqueous solutions of urea. Drug solutions of different concentrations were then prepared by dilution of the stock solution with the respective solvents.

\subsection{Density measurement.}

The pycnometer used to measure the density of the solutions was calibrated with deionized double distilled water. Densities of the solutions of diclofenac potassium in water and in water + urea media were measured at $298.15 \mathrm{~K}, 303.15 \mathrm{~K}, 308.15 \mathrm{~K}$ and $313.15 \mathrm{~K}$. The temperature was maintained constant at a desired degree by using a hot water thermostat. Density values of water at a specific temperature were obtained from literature [11]. The precision of density measurement was within $\pm .02 \%$.

\subsection{Ultrasonic measurement.}

The ultrasonic velocity in the solutions as well as in the solvents was measured with an ultrasonic interferometer (Mittal Enterprise, New Delhi), operating at a frequency of $2 \mathrm{MHz}$. The temperature of the solution was maintained at $298.15 \mathrm{~K}$ by thermostatically regulated water bath. The velocity measurement was within $\pm 0.5 \mathrm{~ms}^{-1}$ accuracy [12]. 
Table 1. Symbols in order of their appearance.

\begin{tabular}{|c|c|c|}
\hline Symbols & Parameters & Units \\
\hline $\begin{array}{l}\mathrm{V}_{\phi} \& \mathrm{~V}_{\phi}^{0} \\
\mathrm{c} \\
\mathrm{d} \& \mathrm{~d}_{0} \\
E_{\phi} \& \mathrm{E}_{\phi}^{0} \\
\alpha \& \alpha_{0} \\
\mathrm{U} \\
\mathrm{K}_{\mathrm{s}} \\
\mathrm{K}_{\mathrm{s}, \phi} \\
\mathrm{K}_{\mathrm{T}} \\
\mathrm{Z} \\
\mathrm{R}_{\mathrm{A}} \\
\pi_{\mathrm{i}} \\
\mathrm{b} \\
\mathrm{V}_{\mathrm{f}} \\
\mathrm{W}\end{array}$ & $\begin{array}{c}\text { Apparent \& limiting apparent molar volume respectively } \\
\text { Molar concentration } \\
\text { Density of solution and solvent respectively } \\
\text { Apparent \& limiting apparent molar expansibility respectively } \\
\text { Coefficient of thermal expansion of solution and solvent } \\
\text { respectively } \\
\text { Ultrasonic velocity in solution } \\
\text { Molar isentropic compressibility } \\
\text { Apparent molar isentropic compressibility } \\
\text { Isothermal compressibility } \\
\text { Acoustic impedance } \\
\text { Relative ion association } \\
\text { Internal pressure } \\
\text { van der Waals constant } \\
\text { Molar free volume } \\
\text { Molar compressibility }\end{array}$ & $\begin{array}{l}\mathrm{m}^{3} \cdot \mathrm{mol}^{-1} \\
\mathrm{~mol} \cdot \mathrm{m}^{-3} \\
\mathrm{~kg} \cdot \mathrm{m}^{-3} \\
\mathrm{~m}^{3} \cdot \mathrm{mol}^{-1} \mathrm{~K}^{-1} \\
\mathrm{~K}^{-1} \\
\mathrm{~m} \mathrm{~s}^{-1} \\
\mathrm{~ms}^{-2} \mathrm{~kg}^{-1} \\
\mathrm{~m}^{2} \cdot \mathrm{N}^{-1} \\
\mathrm{~m}^{4} \mathrm{~kg} \cdot \mathrm{mol}^{2} \mathrm{~s}^{2} \\
\mathrm{~kg} \cdot \mathrm{m}^{2} \mathrm{~s} \\
\mathrm{~m}^{3} \cdot \mathrm{mol}^{-1} \\
\mathrm{~N} \cdot \mathrm{m}^{-2} \\
\mathrm{~m}^{3} \cdot \mathrm{mol}^{-1} \\
\mathrm{~m}^{3} \cdot \mathrm{mol}^{-1}\end{array}$ \\
\hline
\end{tabular}

\subsection{Calculation.}

The apparent molar volume $\mathrm{V}_{\phi}$ was calculated by the following equation [13]

$$
\mathrm{V}_{\phi}=\left[1000 / \mathrm{cd}_{0}\right]\left(\mathrm{d}_{0}-\mathrm{d}\right)+\left(1 / \mathrm{md}_{0}\right)
$$

$\mathrm{V}_{\phi}$ data were fitted into Masson equation.

$$
\mathrm{V}_{\phi}=\mathrm{V}_{\phi}^{0}+\mathrm{S}_{\mathrm{V}} \sqrt{\mathrm{c}}
$$

Plot of $V_{\phi} \mathrm{vs} \sqrt{c}$ shows a linear relationship. $V_{\phi}^{0}$ is the intercept and $S_{V}$ is the slope of the straight line.

Apparent molar expansibility $E_{\phi}$ was calculated from eq. (3).

$$
E_{\phi}=\alpha_{0} \mathrm{~V}_{\phi}+\left(\alpha-\alpha_{0}\right) 1000 \mathrm{c}^{-1}
$$

Where $\alpha_{0}=-1 / \mathrm{d}_{0}\left(\delta \mathrm{d}_{0} / \delta_{\mathrm{t}}\right)_{\mathrm{p}}$ and

$$
\alpha=-1 / \mathrm{d}\left(\delta \mathrm{d}_{0} / \delta_{\mathrm{t}}\right)_{\mathrm{p}}
$$

$\alpha$ and $\alpha_{0}$ are the coefficients of thermal expansion of solution and solvent respectively $[14,15]$. $E_{\phi}$ data were also fitted into Masson equation [36]. From the intercept and slope of $E_{\phi}$ vs $\sqrt{\mathrm{c}}$ we got the values of apparent limiting molar expansibility $E_{\phi}^{0}$ and $\mathrm{S}_{\mathrm{E}}$ respectively.

$$
E_{\phi}=\mathrm{E}_{\phi}^{0}+\mathrm{S}_{\mathrm{E}} \sqrt{\mathrm{c}}
$$

Adiabatic isentropic compressibility $\mathrm{K}_{\mathrm{S}}$ has been calculated by using eq 6 ,

$$
\mathrm{K}_{\mathrm{s}}=\frac{1}{\mathrm{dU}^{2}}
$$

$\mathrm{K}_{\mathrm{s}, \phi}$ has been computed from eq7.

$$
\begin{aligned}
\mathrm{K}_{\mathrm{s}, \phi} & =1000 \mathrm{~K}_{\mathrm{s}} \mathrm{c}^{-1}-\mathrm{K}_{\mathrm{s}}^{0} \mathrm{~d}_{0}{ }^{-1}\left(1000 \mathrm{c}^{-1} \mathrm{~d}-\mathrm{M}\right) \\
\mathrm{K}_{\mathrm{T}} & =\frac{17.1 \times 10^{-4}}{T^{4} / 9 . \mathrm{d}^{4} / 3 \cdot \mathrm{U}^{2}}
\end{aligned}
$$

Parameters like acoustic impedance $(\mathrm{Z})$, relative association $\left(\mathrm{R}_{\mathrm{A}}\right)$, intermolecular free volume $\left(\mathrm{V}_{\mathrm{f}}\right)$, internal pressure $\left(\pi_{\mathrm{i}}\right)$, van der Waals constant (b) and molar compressibility (W) can be calculated from the following relations eq. 9- 15 [16-18].

$$
\begin{aligned}
& \mathrm{Z}=\mathrm{Ud} \\
& \mathrm{R}_{\mathrm{A}}=\left(\mathrm{d} / \mathrm{d}_{0}\right)\left(\mathrm{U}_{0} / \mathrm{U}\right)^{1 / 3} \\
& \mathrm{~V}_{\mathrm{f}}=\mathrm{V}_{\mathrm{m}}-\mathrm{b} \\
& \text { Where } \mathrm{V}_{\mathrm{m}}=\overline{\mathrm{M}} / \mathrm{d} \\
& \pi_{\mathrm{i}}=\left(\mathrm{K}_{\mathrm{s}}{ }^{0}-\mathrm{K}_{\mathrm{s}}\right) \\
& \mathrm{b}=\overline{\mathrm{M}} / \mathrm{d}\left[1-\left(\mathrm{RT} / \overline{\mathrm{M}} \mathrm{U}^{2}\right)\left\{\left(1+\overline{\mathrm{M}} \mathrm{U}^{2} / 3 \mathrm{RT}\right)^{1 / 2}-1\right\}\right] \\
& \mathrm{W}=\overline{\mathrm{M}} / \mathrm{K}_{\mathrm{s}}{ }^{1 / 7} \mathrm{~d}
\end{aligned}
$$




\section{Results and Discussion}

\subsection{Volumetric studies.}

Volumetric studies are an important means of understanding ionic interactions existing in solutions [18]. The experimental density data for diclofenac potassium in 2, 3 and $4 \mathrm{M}$ aqueous urea solutions at 4 different temperatures ranging from $298.15 \mathrm{~K}$ to $313.15 \mathrm{~K}$ are presented in Table 2. It is observed that at a given temperature density of the solution increases with an increase in concentration of diclofenac potassium as well as of urea in solution. The increase in density with increasing urea concentration is an indication of replacement of water molecules from the solvation shell with urea. That results in stronger solute-solvent attraction, shrinkage in volume and increase in density. As it was expected density value decreases with an increase in temperature because of the weakening of the solute-solvent bonds at higher temperature [19].

Table 2. Values of density, $\mathrm{d}\left(\mathrm{kg} . \mathrm{m}^{-3}\right)$ of solutions of diclofenac potassium of different concentrations, $\mathrm{c}$

\begin{tabular}{|c|c|c|c|c|c|}
\hline \multirow{2}{*}{$\begin{array}{c}\text { Molar } \\
\text { Composition } \\
\text { of Urea }\end{array}$} & \multirow{2}{*}{$\begin{array}{c}\text { Conc. of Diclofenac } \\
\text { potassium } \\
\left(\mathrm{mol}^{-3} \mathrm{~m}^{-3}\right)\end{array}$} & \multicolumn{4}{|c|}{$\begin{array}{c}\text { Density } \\
\left(\mathrm{kg} \cdot \mathrm{m}^{-3}\right)\end{array}$} \\
\hline & & $298.15 \mathrm{~K}$ & $303.15 \mathrm{~K}$ & $308.15 \mathrm{~K}$ & $313.15 \mathrm{~K}$ \\
\hline \multirow{7}{*}{2} & 16 & 1185.5 & 1181.4 & 1178.1 & 1177.0 \\
\hline & 14 & 1182.1 & 1178.0 & 1174.7 & 1173.6 \\
\hline & 12 & 1179.1 & 1175.4 & 1172.1 & 1171.0 \\
\hline & 10 & 1174.5 & 1170.4 & 1167.2 & 1166.1 \\
\hline & 08 & 1168.5 & 1164.4 & 1161.1 & 1160.1 \\
\hline & 06 & 1165.7 & 1161.6 & 1158.4 & 1157.3 \\
\hline & 04 & 1160.5 & 1156.4 & 1153.2 & 1152.1 \\
\hline \multirow{7}{*}{3} & 16 & 1189.2 & 1185.4 & 1182.4 & 1181.7 \\
\hline & 14 & 1185.3 & 1181.5 & 1178.6 & 1177.9 \\
\hline & 12 & 1180.0 & 1176.3 & 1173.4 & 1172.6 \\
\hline & 10 & 1175.9 & 1172.0 & 1169.1 & 1168.3 \\
\hline & 08 & 1172.5 & 1168.8 & 1165.8 & 1165.0 \\
\hline & 06 & 1169.1 & 1165.4 & 1162.5 & 1161.7 \\
\hline & 04 & 1165.4 & 1161.6 & 1158.7 & 1158.0 \\
\hline \multirow{7}{*}{4} & 16 & 1191.9 & 1188.5 & 1186.0 & 1183.2 \\
\hline & 14 & 1187.5 & 1184.1 & 1181.6 & 1179.8 \\
\hline & 12 & 1183.2 & 1179.9 & 1177.3 & 1175.5 \\
\hline & 10 & 1177.6 & 1174.3 & 1171.8 & 1170.0 \\
\hline & 08 & 1173.2 & 1169.9 & 1167.4 & 1166.6 \\
\hline & 06 & 1171.3 & 1167.9 & 1165.4 & 1163.6 \\
\hline & 04 & 1166.5 & 1163.2 & 1161.7 & 1159.9 \\
\hline
\end{tabular}

\subsubsection{Molar volume.}

Apparent molar volume, $\mathrm{V}_{\phi}$ defines the change in the volume of the solution per mole of solute added to the solution. $\mathrm{V}_{\phi}$ value is an indication of solute-solvent interaction. The values of $\mathrm{V}_{\phi}$ are subjective to the size of the solvated solute molecules which may be influenced by a change in solvent, concentration of the solutions and temperature [20]. $V_{\phi}$ for the solutions of diclofenac potassium with varying concentrations in 2, 3 and $4 \mathrm{M}$ aqueous urea have been calculated by using equation (1). Negative values of $\mathrm{V}_{\phi}$ for all the solutions are attributed to weaker solute-solvent interaction. $\mathrm{V}_{\phi}$ values show regular increments with concentration of the drug and that of the hydrotropic agent as well in the solution. Increasing values of $\mathrm{V}_{\phi}$ with concentration may be a result of the structure breaking properties of the solvent. With increasing temperature attraction between solute and solvent particles decreases causing $\mathrm{V}_{\phi}$, that means, solute-solvent interaction to depreciate. Variation of $\mathrm{V}_{\phi}$ with square 
root of varying concentration of diclofenac poatassium solutions in $3 \mathrm{M}$ aqueous urea at $298.15 \mathrm{~K}$ is presented in Fig 1a.

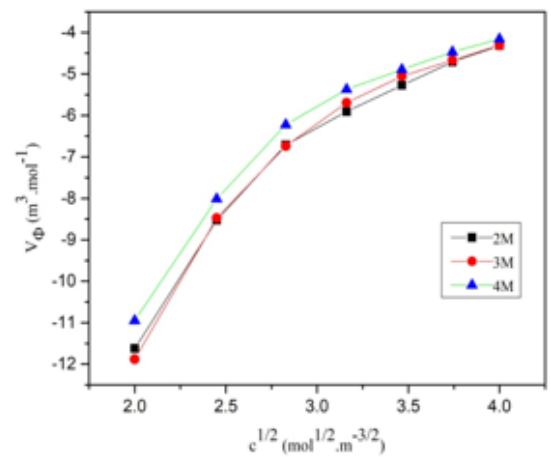

(a)

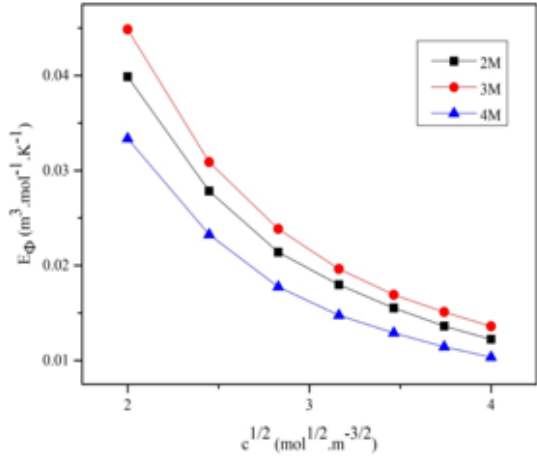

(b)

Figure 1. Variation of (a) aparent molar volume $V_{\phi}$ and (b) aparent molar expansibility $E_{\phi}$ with square root of concentration c at $298.15 \mathrm{~K}$.

Linear relationship of $\mathrm{V}_{\phi}($ eq 2$)$ and $\mathrm{E}_{\phi}($ eq 5) with square root of concentration leads to the calculation of limiting apparent molar volume $V_{\phi}^{0}$ and limiting apparent molar expansibility $\mathrm{E}_{\phi}^{0}$ respectively by least square fitting method in Masson equation. The values of $\mathrm{V}_{\phi}^{0}$ along with $E_{\phi}^{0}, \mathrm{~S}_{\mathrm{v}}$ and $\mathrm{S}_{\mathrm{E}}$ for all the solutions with different concentrations of Diclofenac potassium and also of urea at 4 different temperatures are displayed in Table 3.

Table 3. Values of parameters $\mathrm{V}_{\phi}^{0}\left(\mathrm{~m}^{3} \mathrm{~mol}^{-1}\right), \mathrm{S}_{\mathrm{V}}\left(\mathrm{m}^{3 / 2} \mathrm{~mol}^{-3 / 2}\right), \mathrm{E}_{\phi}^{0}\left(\mathrm{~m}^{3} \mathrm{~mol}^{-1} \mathrm{~K}^{-1}\right)$ and $\left.\mathrm{S}_{\mathrm{E}}\left(\mathrm{m}^{3 / 2} \mathrm{~mol}^{3 / 2}\right) \mathrm{K}^{-1}\right)$ for diclofenac potassium in aqueous solutions of urea at different temperatures $T(K)$.

\begin{tabular}{|c|c|c|c|c|c|}
\hline $\begin{array}{c}\text { Molar composition } \\
\text { of aq. urea }\end{array}$ & $\begin{array}{l}\text { Temp } \\
(\mathrm{K})\end{array}$ & $\mathrm{V}_{\phi}^{0}\left(\mathrm{~m}^{3} \mathrm{~mol}^{-1}\right)$ & $\mathrm{Sv}\left(\mathrm{m}^{3 / 2} \mathrm{~mol}^{-3 / 2}\right)$ & $\begin{array}{c}\mathrm{E}_{\phi}^{0} \\
\left(\mathrm{~m}^{3} \mathrm{~mol}^{-1} \mathrm{~K}^{-1}\right)\end{array}$ & $\begin{array}{c}\mathrm{S}_{\mathrm{E}} \\
\left(\mathrm{m}^{3 / 2} \mathrm{~mol}^{3 / 2} \mathrm{~K}^{-1}\right)\end{array}$ \\
\hline \multirow{4}{*}{2} & 298.15 & -17.411 & 3.4566 & 0.0617 & -0.0131 \\
\hline & 303.15 & -17.439 & 3.4592 & 0.0617 & -0.0131 \\
\hline & 308.15 & -17.506 & 3.4749 & 0.0618 & -0.0131 \\
\hline & 313.15 & -17.572 & 3.489 & 0.0619 & -0.0131 \\
\hline \multirow{4}{*}{3} & 298.15 & -17.769 & 113.31 & 0.0693 & -0.0148 \\
\hline & 303.15 & -17.824 & 113.67 & 0.0694 & -0.0148 \\
\hline & 308.15 & -17.892 & 3.6092 & 0.0695 & -0.0148 \\
\hline & 313.15 & -17.946 & 3.6215 & 0.0696 & -0.0149 \\
\hline \multirow{4}{*}{4} & 298.15 & -16.267 & 101.95 & 0.0514 & -0.0109 \\
\hline & 303.15 & -16.303 & 102.2 & 0.0514 & -0.0109 \\
\hline & 308.15 & -16.336 & 3.2385 & 0.0515 & -0.0109 \\
\hline & 313.15 & -17.44 & 3.5081 & 0.0531 & -0.0113 \\
\hline
\end{tabular}

Variation of $\mathrm{V}_{\phi}^{0}$ with increasing concentration of diclofenac potassium in 2, 3 and $4 \mathrm{M}$ urea solutions at a given temperature is attributed to the influence of the increasing electrostatic fields of the drug ions on the surrounding solvent molecules [21] and is complementing the fact of stronger solute-solute interactions in solutions with higher concentrations of the drug and of urea as well. Negative values of $V_{\phi}^{0}$ for all the solutions studied are results of electrostrictive solvation of the drug molecules.

$S_{v}$, measured from the experimental slope of $V_{\phi}$ vs. $c^{1 / 2}$ plot indicates solute-solute interaction. Positive values of $S_{v}$ suggest the presence of stronger solute-solute interactions in all the liquid mixtures under study. 


\subsubsection{Molar expansibility.}

Apparent molar expansibility $\mathrm{E}_{\phi}$ focuses light on solute-solvent interaction in a solution. As it was expected, $\mathrm{E}_{\phi}$ values for all the solutions with varying concentrations of diclofenac potassium and urea display a positive relation with concentration. The fact is supported by a plot of $\mathrm{E}_{\phi}$ vs. $c^{1} / 2$ for drug solutions at $298.15 \mathrm{~K}$ presented in Fig1b.

Limiting apparent molar expansibility $E_{\phi}^{0}$ describes the kosmotropic, ie. structure making or chaotropic, ie.structure breaking nature of the solvent. Positive values of $E_{\phi}^{0}$ suggest that the process of structure making was in action during the whole experimental temperature range in all the solutions studied. Limiting apparent molar expansibility is attributed to electrostiction or hydration of drug molecules and changes in solvent structure. As it was predicted, $E_{\phi}^{0}$ values for drug solutions with $3 \mathrm{M}$ urea are higher than those with $2 \mathrm{M}$ urea, however, there is a drop in the values with $4 \mathrm{M}$ urea. This may be due to the congestion of particles in $4 \mathrm{M}$ urea that hampers the structure making process.

\subsection{Acoustic studies.}

As velocity of sound depends on the properties of the medium it is traveling through, study of acoustic parameters is proved to be a useful tool for analysis of molecular interactions present in liquid systems. Ultrasonic sound velocities (U) through solutions of diclofenac potassium of different concentrations dissolved in 2, 3 and $4 \mathrm{M}$ aqueous urea solutions were measured at $298.15 \mathrm{~K}$ and the values are presented in Table 4. The ascent of $U$ with concentrations of diclofenac potassium and urea points to the fact that the association between solute and solvent molecules increases with increasing concentrations. The fact is in support of the similar trend of variation of density with concentration.

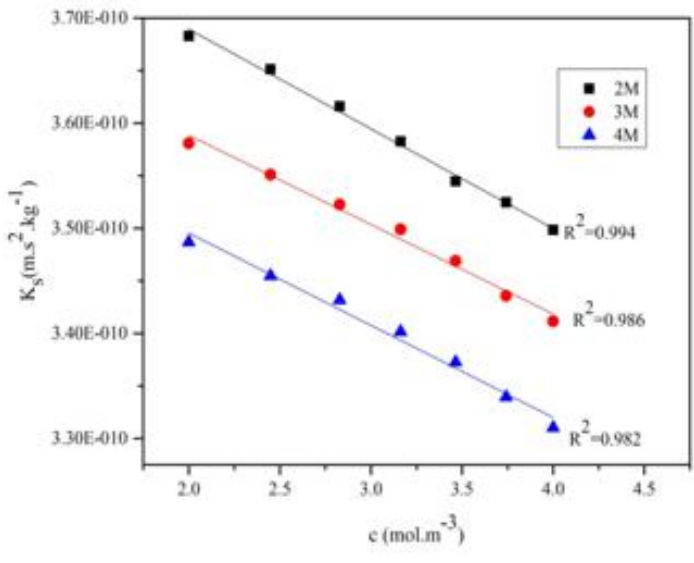

(a)

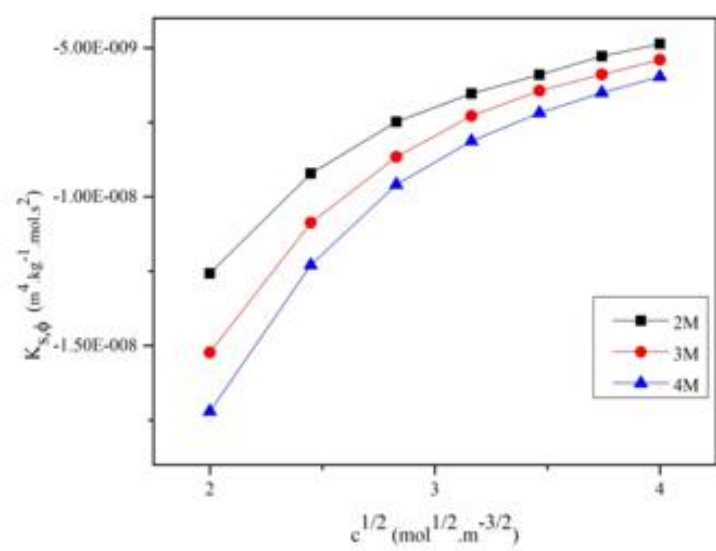

(b)

Figure 2. variation of (a) molar isentropic compressibility $\mathrm{K}_{\mathrm{s}}$ and (b) aparent molar isentropic compressibility $\mathrm{K}_{\mathrm{s}, \phi}$ with concentration $\mathrm{c}$ at $298.15 \mathrm{~K}$.

\subsubsection{Molar compressibility.}

Molar isentropic compressibility $\left(\mathrm{K}_{\mathrm{s}}\right)$ is the relative change in volume of a fluid when entropy remains constant. Change in volume takes place due to the variations in the compactness of the solvation shell around the solute particles. $\mathrm{K}_{\mathrm{s}}$ is calculated by putting the values of density (d) and ultrasonic velocity (U) in eq. 6 . Scrutiny of table 3 reveals that there is a diminishing trend in compressibility with increasing concentration of the drug, as well as 
of urea. An explanation of this fact may be that increasing number of particles in the solution makes compression of the hydration shell around the solute difficult at higher concentration of drug in the solution $[22,23]$ With increasing urea content in solution, the interstitial spaces of water molecules are occupied with urea and that makes a tight structure around the drug molecules. As a support to this explanation variation of $\mathrm{K}_{s}$ with varying concentrations of drug in solutions with varying content of hydrotropic agent at $298.15 \mathrm{~K}$ is presented in Fig $2 \mathrm{a}$.

Table 4. Concentration of diclofenac potassium $\mathrm{c}\left(\mathrm{mol} \cdot \mathrm{m}^{-3}\right)$, density d $\left(\mathrm{kg} \cdot \mathrm{m}^{-3}\right)$, sound velocity $\mathrm{U}\left(\mathrm{m} \cdot \mathrm{s}^{-1}\right)$, molar isentropic compressibility $\mathrm{K}_{\mathrm{s}}\left(\mathrm{m} \cdot \mathrm{s}^{2} \cdot \mathrm{kg}^{-1}\right)$, apparent molar isentropic compressibility $\mathrm{K}_{\mathrm{s}, \phi}\left(\mathrm{m}^{4} \cdot \mathrm{kg} \cdot \mathrm{mol} \cdot \mathrm{s}^{2}\right)$, molar adiabatic compressibility $\mathrm{W}$, molar isothermal compressibility $\mathrm{K}_{\mathrm{T}}\left(\left(\mathrm{m}^{2} \cdot \mathrm{N}^{-1}\right)\right.$ in aqueous solutions of

\begin{tabular}{|c|c|c|c|c|c|c|c|}
\hline $\begin{array}{c}\text { Molar } \\
\text { composition of } \\
\text { aq. Urea }\end{array}$ & $\begin{array}{l}\text { Conc. of } \\
\text { diclofenac } \\
\text { potassium } \\
\left(\mathrm{mol} . \mathrm{m}^{-3}\right) \\
\end{array}$ & $\left(\mathrm{kg} \cdot \mathrm{m}^{-3}\right)$ & $\begin{array}{l}\text { urea a } \\
\mathrm{U} \\
\left(\mathrm{m} \cdot \mathrm{s}^{-1}\right)\end{array}$ & $\begin{array}{l}98.15 \mathrm{~K} . \\
\mathrm{K}_{\mathrm{s}} \times 10^{10} \\
\left(\mathrm{~m} \cdot \mathrm{s}^{2} \cdot \mathrm{kg}^{-1}\right)\end{array}$ & $\begin{array}{c}\mathrm{K}_{\mathrm{s}, \phi} \times 10^{9} \\
\left(\mathrm{~m}^{4} \cdot \mathrm{kg} \cdot \mathrm{mol} \cdot \mathrm{s}^{2}\right)\end{array}$ & $\mathrm{W} \times 10^{5}$ & $\begin{array}{r}\mathrm{K}_{\mathrm{T}} \times 10^{15} \\
\left(\mathrm{~m}^{2} \cdot \mathrm{N}^{-1}\right)\end{array}$ \\
\hline \multirow[t]{7}{*}{2} & 16 & 1185.5 & 1552.8 & 3.498 & -04.860 & 36.83 & 4.49 \\
\hline & 14 & 1182.1 & 1549.2 & 3.525 & -05.279 & 36.88 & 4.53 \\
\hline & 12 & 1179.1 & 1546.8 & 3.545 & -05.902 & 36.93 & 4.56 \\
\hline & 10 & 1174.5 & 1541.6 & 3.583 & -06.537 & 37.01 & 4.61 \\
\hline & 08 & 1168.5 & 1538.4 & 3.616 & -07.483 & 37.14 & 4.67 \\
\hline & 06 & 1165.7 & 1532.8 & 3.651 & -09.222 & 37.17 & 4.72 \\
\hline & 04 & 1160.5 & 1529.6 & 3.683 & -12.572 & 37.28 & 4.76 \\
\hline \multirow[t]{7}{*}{3} & 16 & 1189.2 & 1570.0 & 3.412 & -05.401 & 38.30 & 4.38 \\
\hline & 14 & 1185.3 & 1567.0 & 3.436 & -05.898 & 38.38 & 4.41 \\
\hline & 12 & 1180.0 & 1563.0 & 3.469 & -06.447 & 38.49 & 4.46 \\
\hline & 10 & 1175.9 & 1559.0 & 3.499 & -07.289 & 38.57 & 4.51 \\
\hline & 08 & 1172.5 & 1556.0 & 3.523 & -08.662 & 38.64 & 4.54 \\
\hline & 06 & 1169.1 & 1552.0 & 3.551 & -10.871 & 38.70 & 4.58 \\
\hline & 04 & 1165.4 & 1548.0 & 3.581 & -15.232 & 38.77 & 4.62 \\
\hline \multirow[t]{7}{*}{4} & 16 & 1191.9 & 1592.0 & 3.310 & -05.973 & 39.95 & 4.24 \\
\hline & 14 & 1187.5 & 1588.0 & 3.339 & -06.506 & 40.04 & 4.29 \\
\hline & 12 & 1183.2 & 1583.0 & 3.373 & -07.185 & 40.13 & 4.33 \\
\hline & 10 & 1177.6 & 1580.0 & 3.402 & -08.132 & 40.28 & 4.38 \\
\hline & 08 & 1173.2 & 1576.0 & 3.432 & -9.592 & 40.38 & 4.42 \\
\hline & 06 & 1171.3 & 1572.0 & 3.455 & -12.292 & 40.39 & 4.45 \\
\hline & 04 & 1166.5 & 1568.0 & 3.487 & -17.210 & 40.51 & 4.50 \\
\hline
\end{tabular}

Apparent molar isentropic compressibility $\mathrm{K}_{\mathrm{s}, \phi}$ has been computed from eq. 9 and the values are presented in Table 3. Compression of the solvation shells around the drug molecules can further be explained with the help of $\mathrm{K}_{\mathrm{s}, \phi}$. Negative values of $\mathrm{K}_{\mathrm{s}, \phi}$ for the whole range of concentration of the drug in all compositions of the hydrotropic agent indicate towards two factors, namely, electrostriction and hydrophobic solvation. Due to strong elctrostriction in the vicinity of the ions compressibility of the solvation shells is affected and only a little compression takes place when pressure is applied [24,25]. There is a loss of compressibility of the hydration shells around the hydrophobic drug molecules with increasing urea content because of the replacement of water molecules with urea in the solvation shells. Apparent molar isentropic compressibility increases with increasing drug concentration [26]. The phenomenon is presented in Fig $2 \mathrm{~b}$ in which plots of $\mathrm{K}_{\mathrm{s}, \phi}$ with varying drug concentration and urea content in the ternary mixtures at $298.15 \mathrm{~K}$ are displayed.

Apparent molar isothermal compressibility $\mathrm{K}_{\mathrm{T}}$ bears a descending linear relationship with concentrations of both the drug and the hydrotropic agent in the solutions (Fig 3a). This trend may be attributed to the larger electrostrictive compression of the solvent molecules surrounding the ions that leads to a decrease in compressibility of solution at higher concentrations. 


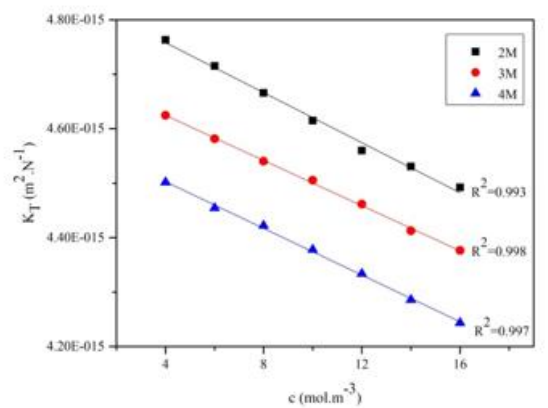

(a)

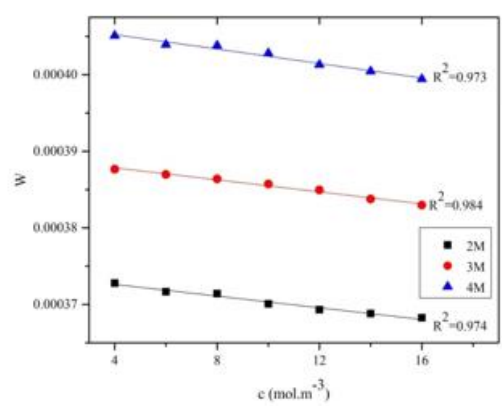

(b)

Figure 3. variation of (a) molar isothermal compressibility $K_{T}$ and (b) molar adiabatic compressibility W with concentration c at $298.15 \mathrm{~K}$.

Molar adiabatic compressibility (W) is another important parameter in studying molecular interactions in solutions. A scrutiny of Table 4 reveals that $\mathrm{W}$ increases with the increasing amount of hydrotropic agent but diminishes with concentration of the drug solute in solution (Fig 3b).

\subsubsection{Other acoustic parameters.}

In the attempt of achieving a deeper understanding of solute-solute and solute-solvent interactions some other acoustic parameters are evaluated and interpreted. Parameters like relative association $\left(R_{A}\right)$, acoustic impedance $(Z)$, intermolecular free volume $\left(V_{f}\right)$, internal pressure $\left(\pi_{\mathrm{i}}\right)$, co-efficient of thermal expansion $\alpha\left(\mathrm{K}^{-1}\right)$, heat capacity ratio $\gamma$ and van der Waals constant (b) for the drug solutions in aqueous urea medium can be calculated from the relations in equation (11)-(21). The values are summarized in Table 5 .

Relative association $\left(R_{A}\right)$ is a result of two factors- i) splitting of associated solvent molecules with the introduction of solute molecules in the solution and ii) consequent solvation of the solute molecules. Increasing values of $\mathrm{R}_{\mathrm{A}}$ implies increased association of the solute and solvent molecules with increasing concentration of the drug solute[27]. On the other hand a linear decrease of $\mathrm{R}_{\mathrm{A}}$ with increasing urea content supports the structure breaking action of the hydrotropic agent that in turn promotes solvation of the drug molecules. Fig $4 \mathrm{a}$ is presented in support of the statement.

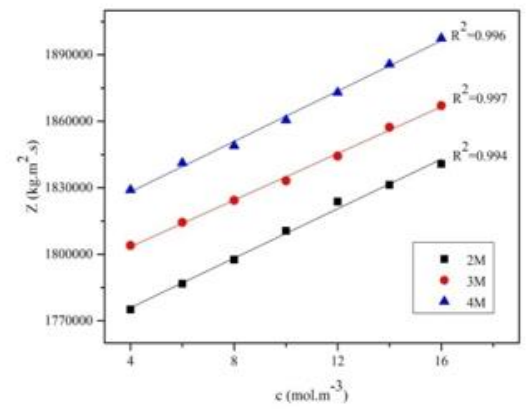

(a)

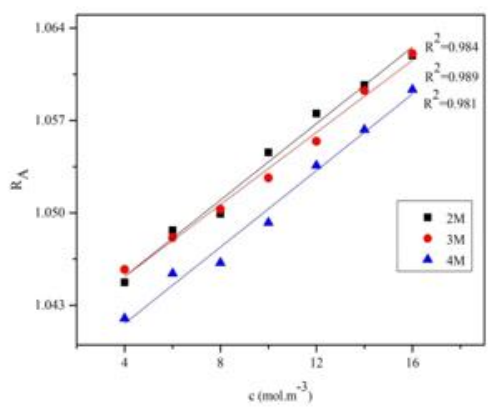

(b)

Figure 4. Variation of (a) relative ion association $R_{A}$ and (b) acoustic impedance $\mathrm{Z}$ with concentration cat $298.15 \mathrm{~K}$.

Acoustic impedance $\mathrm{Z}$ is the measure of resistance encountered by the ultrasound beam while passing through a medium. It is a function of elastic property of the medium. Ascending 
trend of $\mathrm{Z}$ with drug concentration, as well as with urea content in Fig $4 \mathrm{~b}$ is holding up the fact of structural changes and gain of elastic properties in the solutions [28].

Free volume $\mathrm{V}_{\mathrm{f}}$ is the effective volume available to the solute molecules to move about in a liquid. $\mathrm{V}_{\mathrm{f}}$ is a measure of repulsive forces whereas internal pressure $\pi_{\mathrm{i}}$ is a measure of attractive forces that bind the liquid molecules together. The two factors together determine the entropy of the system. These factors are the thermodynamic variables necessary to describe a liquid system. Negative values of $\mathrm{V}_{\mathrm{f}}$ are in agreement with the fact that strong attractive forces are acting between the solute and solvent molecules in all the solutions [29]. The presence of hydrotropic agents in the solution further reduces the repulsion between the solute and solvent molecules and enhances the solvation of poorly water soluble drug in the liquid mixture. The variation of $\mathrm{V}_{\mathrm{f}}$ and $\pi_{\mathrm{i}}$ with concentration of drug and amount of hydrotropic agent in the solution (presented in Fig 5a and b) supports the fact of strong molecular interaction and binding force between solute and solvent particles in solution [30,31].

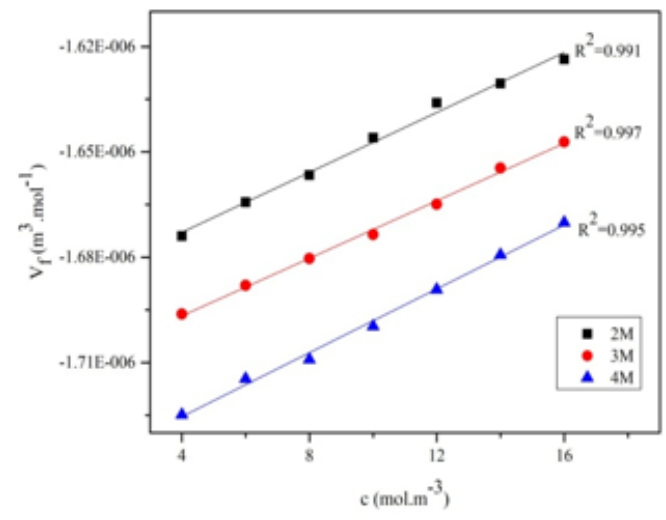

(a)

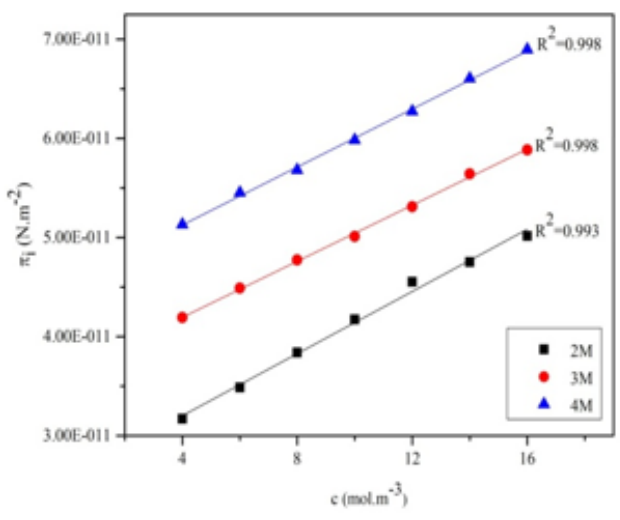

(b)

Figure 5. Variation of (a) molar free volume $V_{\mathrm{f}}$ and (b) internal pressure $\pi_{i}$ with concentration c at $298.15 \mathrm{~K}$.

Table 5. Concentration of diclofenac potassium c $\left(\mathrm{mol} \cdot \mathrm{m}^{-3}\right)$, internal pressure $\pi_{\mathrm{i}}\left(\mathrm{N} \cdot \mathrm{m}^{-2}\right)$, acoustic impedance $\mathrm{Z}\left(\mathrm{kg} \cdot \mathrm{m}^{2} . \mathrm{s}\right)$, vander Waals constant $\mathrm{b}\left(\mathrm{m}^{3} \cdot \mathrm{mol}^{-1}\right)$, molar free volume $\mathrm{V}_{\mathrm{f}}\left(\mathrm{m}^{3} \cdot \mathrm{mol}^{-1}\right)$, relative ion association $\mathrm{R}_{\mathrm{A}}$ and co-efficient of thermal expansion $\alpha\left(K^{-1}\right)$ in aqueous solutions of urea at $298.15 \mathrm{~K}$.

\begin{tabular}{|c|c|c|c|c|c|c|c|}
\hline $\begin{array}{c}\text { Molar } \\
\text { composition of } \\
\text { aq. urea } \\
\end{array}$ & $\begin{array}{l}\text { Conc. of } \\
\text { diclofenac } \\
\left(\mathrm{mol} . \mathrm{m}^{-3}\right) \\
\end{array}$ & $\left.\mathrm{m}^{-2}\right)$ & $\begin{array}{l}\mathrm{Z} \times 10^{-5} \\
\left(\mathrm{~kg} \cdot \mathrm{m}^{2} . \mathrm{s}\right)\end{array}$ & $\begin{array}{c}\mathrm{b} \times 10^{6} \\
\left(\mathrm{~m}^{3} \cdot \mathrm{mol}^{-1}\right)\end{array}$ & $\begin{array}{l}\mathrm{V}_{\mathrm{f}} \times 10^{7} \\
\left(\mathrm{~m}^{3} \cdot \mathrm{mol}^{-1}\right)\end{array}$ & $\mathrm{R}_{\mathrm{A}}$ & $\mid \begin{array}{l}\alpha \times 10^{5} \\
\left(K^{-1}\right)\end{array}$ \\
\hline \multirow{7}{*}{2} & 16 & 5.02 & 18.408 & 18.04 & -16.24 & 1.062 & 9.66 \\
\hline & 14 & 4.75 & 18.313 & 18.09 & -16.31 & 1.060 & 9.68 \\
\hline & 12 & 4.55 & 18.238 & 18.13 & -16.36 & 1.058 & 9.69 \\
\hline & 10 & 4.17 & 18.106 & 18.20 & -16.46 & 1.055 & 9.72 \\
\hline & 08 & 3.84 & 17.976 & 18.29 & -16.57 & 1.050 & 9.75 \\
\hline & 06 & 3.49 & 17.868 & 18.33 & -16.64 & 1.048 & 9.78 \\
\hline & 04 & 3.17 & 17.751 & 18.41 & -16.74 & 1.045 & 9.79 \\
\hline \multirow{7}{*}{3} & 16 & 5.88 & 18.670 & 18.66 & -16.47 & 1.062 & 9.59 \\
\hline & 14 & 5.64 & 18.574 & 18.72 & -16.55 & 1.059 & 9.61 \\
\hline & 12 & 5.31 & 18.443 & 18.80 & -16.65 & 1.055 & 9.64 \\
\hline & 10 & 5.01 & 18.332 & 18.87 & -16.74 & 1.053 & 9.66 \\
\hline & 08 & 4.77 & 18.244 & 18.92 & -16.80 & 1.050 & 9.68 \\
\hline & 06 & 4.49 & 18.144 & 18.98 & -16.88 & 1.048 & 9.71 \\
\hline & 04 & 4.19 & 18.040 & 19.03 & -16.96 & 1.046 & 9.73 \\
\hline \multirow{7}{*}{4} & 16 & 6.89 & 18.975 & 19.34 & -16.70 & 1.059 & 9.52 \\
\hline & 14 & 6.61 & 18.857 & 19.34 & -16.79 & 1.056 & 9.54 \\
\hline & 12 & 6.27 & 18.730 & 19.41 & -16.89 & 1.054 & 9.57 \\
\hline & 10 & 5.98 & 18.606 & 19.49 & -16.99 & 1.049 & 9.59 \\
\hline & 08 & 5.68 & 18.489 & 19.58 & -17.09 & 1.046 & 9.62 \\
\hline & 06 & 5.45 & 18.413 & 19.66 & -17.15 & 1.045 & 9.64 \\
\hline & 04 & 5.13 & 18.291 & 19.77 & -17.25 & 1.042 & 9.66 \\
\hline
\end{tabular}


Van der Waals constant (b) is a measure of binding forces existing between solute and solvent molecules in a solution. Increasing values of $b$ reveal that the attraction between solute and solvent molecules becomes stronger with increasing drug concentration in aqueous urea media with higher molarity (Fig 6a).

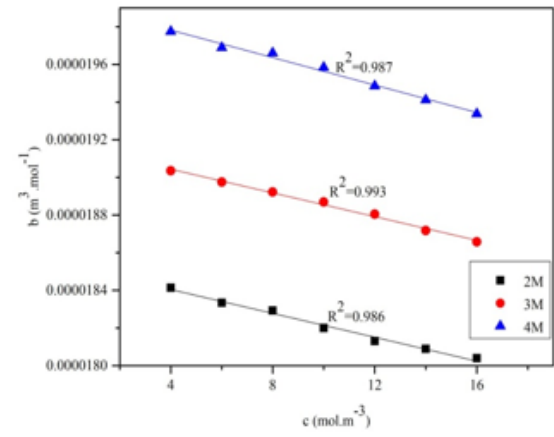

(a)

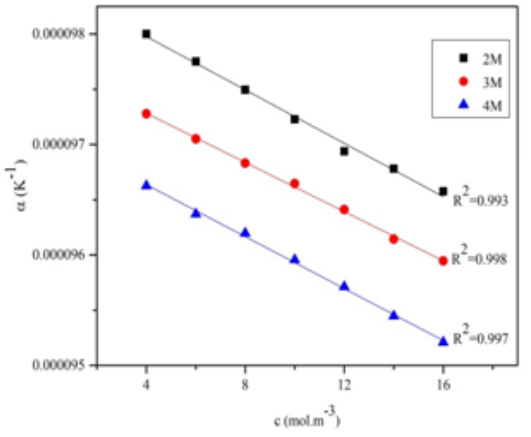

(b)

Figure 6. Variation of (a) van der Waals constant b and (b) coefficient of thermal expansion $\alpha$ with concentration $\mathrm{c}$.

The variation of co-efficient of thermal expansion $(\alpha)$ with concentrations of diclofenac potassium and of urea in solution is linear but negative, as shown in Fig 6b. An increase in concentration increases the compactness of the medium, reduces the intermolecular free length and restricts the thermal expansion. A decrease in $\alpha$ also causes a decrease in isentropic compressibility and isothermal compressibility [32].

\section{Conclusions}

In this article we have reported the volumetric and acoustic properties of a drug diclofenac potassium dissolved in aqueous solutions of hydrotropic agent urea. Diclofenac potassium is found in water as pharmaceutical waste and is proven to be harmful to aquatic life. Urea gets added to water with agricultural runoff. Various physico-chemical properties are derived from the density and ultrasonic values obtained from experiments performed on drug solutions of different concentrations in different molar compositions of aqueous urea media at different temperatures. Variations of these parameters with concentrations of drug, as well as of urea and temperature have been interpreted in terms of solute- solute and solute- solvent interactions present in the ternary mixtures. Negative $\mathrm{V}_{\phi}$ and positive $S_{v}$ values indicate that solute-solute interaction is stronger than solute-solventinteraction in the solutions. However, with the use of hydrotropic agent solute- solvent interaction increases because of the structure making properties of the solvents, as supported by the positive values of $E_{\phi}$. With increasing concentration of urea compressibility of the drug solutions decreased because of the replacement of water molecules from the salvation shells with urea. All other derived acoustic parameters like relative association $R_{A}$ acoustic impedance $Z$, intermolecular free volume $V_{f}$, internal pressure $\pi_{i}$, co-efficient of thermal expansion $\alpha$, heat capacity ratio $\gamma$ and van der Waals constant $b$ support the fact of increased solute-solvent interactions present in solutions under investigation.

\section{Funding}

This research received no external funding.. 


\section{Acknowledgments}

The authors express their heartfelt gratitude to Siksha O Anusandhan deemed to be university for providing the research facility.

\section{Conflicts of Interest}

The authors declare no conflict of interest.

\section{References}

1. Tahvildari, K; Bigdeli, T, Treatment of pharmaceutical wastewater containing antibiotic with oxidation processes by metallic catalysts, Biointerface Res. Appl. Chem., 2019, 9(2), 3853 - 3859 , https://doi.org/10.33263/BRIAC92.853859.

2. Fekadu, S.; Alemayehu, E.; Dewil, R.; Van der Bruggen, B. Pharmaceuticals in freshwater aquatic environments: A comparison of the African and European challenge. Science of The Total Environment 2019, 654, 324-337, https://doi.org/10.1016/j.scitotenv.2018.11.072.

3. Patneedi, C.B.; Prasadu, K. Impact of pharmaceutical wastes on human life and environment. 2015, 8, 6770.

4. Singh, S.; Talukdar, M.; Dash, U.N. Ultrasonic studies on paracetamol in aqueous solutions of sodium salicylate and nicotinamide. Journal of Molecular Liquids 2018, 249, 815-824, https://doi.org/10.1016/j.molliq.2017.11.099.

5. Kumar, H.; Kumar, V.; Sharma, M.; Behal, I. Studies on the interactions behaviour of polyhydroxy solutes $\mathrm{d}(+)$-glucose and $\mathrm{d}(-)$-fructose in aqueous triammonium citrate solutions over temperature range $\mathrm{T}=(288.15-318.15) \mathrm{K}$. The Journal of Chemical Thermodynamics 2018, 119, 1-12, https://doi.org/10.1016/j.jct.2017.12.003.

6. Kumar, H.; Kumar, S.; Behal, I. Investigations on the temperature dependent volumetric and ultrasonic properties of structural isomers $\mathrm{D}(+)$-glucose and $\mathrm{D}(-)$-fructose in aqueous dipotassium oxalate solutions. The Journal of Chemical Thermodynamics 2019, 138, 229-239, https://doi.org/10.1016/j.jct.2019.06.023.

7. Ankita; Nain, A.K. Volumetric, acoustic and viscometric studies of solute-solute and solute-solvent interactions of isoniazid in aqueous-glucose/sucrose solutions at temperatures from $293.15 \mathrm{~K}$ to $318.15 \mathrm{~K}$. The Journal of Chemical Thermodynamics 2019, 133, 123-134, https://doi.org/10.1016/j.jct.2019.01.024.

8. Ankita; Chand, D.; Nain, A.K. Molecular interactions of drug semicarbazide hydrochloride in aqueous-Dxylose/L-arabinose solutions at different temperatures: Volumetric, acoustic and viscometric study. The Journal of Chemical Thermodynamics 2020, 146, https://doi.org/10.1016/j.jct.2020.106106.

9. Lomesh, S.K.; Bala, M.; Nathan, V. Physicochemical approach to study the solute-solute and solute-solvent interactions of drug Levofloxacin hemihydrate in aqueous sorbitol solutions at different temperatures: Volumetric, acoustic and conductance studies. Journal of Molecular Liquids 2019, 283, 133-146, https://doi.org/10.1016/j.molliq.2019.03.055.

10. Lomesh, S.K.; Nathan, V.; Bala, M.; Thakur, P. Volumetric and acoustic methods for investigating molecular interactions of antibiotic drug doxycycline hyclate in water and in aqueous solution of sodium chloride and potassium chloride at different temperatures (293.15-313.15) K. Journal of Molecular Liquids 2019, 284, 241-251, https://doi.org/10.1016/j.molliq.2019.04.006.

11. Density and Speed of Sound of Sodium Nitroprusside with Aqueous Alcohols. Egyptian Journal of Chemistry 2010, 53, 163-176, https://doi.org/10.21608/ejchem.2010.1210.

12. Saxena, I.; Pathak, R.N.; Kumar, V.; Dev, R. Introduction of ultrasonic interferometer and experimental techniques for determination of ultrasonic velocity, density, viscosity and various thermodynamic parameters. Int. J. Appl. Res. 2015, 1, 562-569.

13. Harned, H.S.; Owen, B.B. The Physical Chemistry of Electrolyte Solution. 3rd edn Reinhold, New York, 1958; pp. 358.

14. Das, S.; Dash, U.N. Studies on solute-solvent interactions of amino acids in water + D-glucose mixtures at different temperatures. J. Chem. Pharm. Res. 2012, 4, 754-762.

15. Talukdar, M. Acoustic and ultrasonic studies of alkali metals and ammonium halides in chitosan solutions at four different temperatures. Indian Journal of Pure and Applied Physics 2013, 51, 202-206. 
16. Rao, G.V.; Sri, P.B.; Sarma, A.; Rambabu, C. Comparative study of theoretical ultrasonic velocities of binary mixtures of methanol and pyridine at different temperatures. Indian Journal of Pure and Applied Physics 2007, 45, 135-142.

17. Baskarana, R.; Kubendran, T.R. Ultrasonic velocity, surface tension and thermoacustical parameters of anisaldehyde + benzene at 313.15K. Int. J. Appl. Sci. Engg. 2007, 5, 115-122.

18. Kaczkowska, E.; Wawer, J.; Tyczyńska, M.; Jóźwiak, M.; Krakowiak, J. The hydration of selected biologically relevant molecules - the temperature effect on apparent molar volume and compression. Journal of Molecular Liquids 2019, 274, 345-352, https://doi.org/10.1016/j.molliq.2018.10.155.

19. Kavitha, R.; Jayakumar, S.; Uma, R. Ultrasonic velocity, density and viscosity of binary liquid mixtures of acetone with toluene,chlorobenzene and nitrobenzene. Int. J. Chem. Appl. 2011, 3, 19-33.

20. Ankita; Nain, A.K. Study on the interactions of drug isoniazid in aqueous-D-xylose/L-arabinose solutions at different temperatures using volumetric, acoustic and viscometric approaches. Journal of Molecular Liquids 2020, 298, https://doi.org/10.1016/j.molliq.2019.112086.

21. Rohankar, P.G.; Aswar, A. Apparent molar volume and apparent molar compressibility of glycine in aqueous vanadyl sulphate solutions at 298.15, 303.15 and 308.15 K. Indian Journal of Chemistry - Section A Inorganic, Physical, Theoretical and Analytical Chemistry 2002, 41, 312-315.

22. Pal, A.; Soni, S. Apparent molar volumes and compressibilities of $\alpha$ - and $\beta$-cyclodextrin in aqueous sulfamethoxazole at different temperatures. Journal of Molecular Liquids 2016, 213, 1-7, https://doi.org/10.1016/j.molliq.2015.10.029.

23. Sarkar, A.; Sinha, B. Volumetric, Acoustic and Transport Properties of Metformin Hydrochloride Drug in Aqueous d-Glucose Solutions at T =(298.15-318.15) K. Journal of Solution Chemistry 2017, 46, 424-445, https://doi.org/10.1007/s10953-017-0584-0.

24. Riyazuddeen; Usmani, M.A. Interactions in (glycylglycine $+1 \mathrm{M}$ aqueous glucose/1M aqueous sucrose) systems at 298.15-323.15K. Thermochimica Acta 2012, 532, 36-40, https://doi.org/10.1016/j.tca.2011.03.024.

25. Singh, S.; Talukdar, M.; Dash, U.N. Solute-solvent and solute-solute interactions of ibuprofen in aqueous and in aqueous solutions of urea, sodium salicylate and nicotinamide by volumetric and interferometric techniques. Journal of Molecular Liquids 2017, 241, 934-945, https://doi.org/10.1016/j.molliq.2017.06.112.

26. Patil, P.P.; Shaikh, V.R.; Patil, P.D.; Borse, A.U.; Patil, K.J. Volumetric, isentropic compressibility and viscosity coefficient studies of binary solutions involving amides as a solute in aqueous and CCl4 solvent systems at 298.15 K. Journal of Molecular Liquids 2018, 264, 223-232, https://doi.org/10.1016/j.molliq.2018.05.062.

27. Kincaid, J.F.; Eyring, H. Free Volumes and Free Angle Ratios of Molecules in Liquids. The Journal of Chemical Physics 1938, 6, 620-629, https://doi.org/10.1063/1.1750134.

28. Mehra, R.; Vats, S. Solute-Solvent interactions of Glycine with urea(Aq)+KBr(Aq) at 298, 308 and $318 \mathrm{~K}$. International Journal of Pharma and Bio Sciences 2010, 1, 523-529.

29. Parveen, S.; Singh, S.; Shukla, D.; Singh, K.P.; Gupta, M.; Shukla, J.P. Study of binary mixtures of THF with methanol and o-cresol — an optical and ultrasonic study. Acta Phys. Polon. 2009, 116, 1011-1017.

30. Nithiyanantham, S.; Sundaram, M.; Jayalakshmi, R. Thermo acoustical studies on some electrolytic solvent mixtures at 303 K. Oriental Journal of Chemistry 2009, 25, 759-761.

31. Mehra, R.; Sajnani, H. Acoustical Parameters of CuCl-KCl System in Acetonitrile-Water Solvent Mixture. Physics and Chemistry of Liquids 2001, 39, 581-588, https://doi.org/10.1080/00319100108030679.

32. Nanda, B.B.; Nanda, B.; Mohanty, P.C. Effect of concentration on thermo acoustic and nonlinearity parameters (B/A) of barium chloride solutions in glycol-water mixtures at 303.15K. Journal of Molecular Liquids 2012, 171, 50-53, https://doi.org/10.1016/j.molliq.2012.03.011. 